3

4

5

6

(1)

(2)

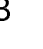
4

\title{
No evidence that lulworthioid fungi are dark septate endophytes in the roots of the dominant Mediterranean seagrass Posidonia oceanica
}

Martin Vohník

Department of Mycorrhizal Symbioses, Institute of Botany, Czech Academy of Sciences, Lesní 322, Průhonice 25243, Czechia

Short title: Root mycobionts of Posidonia oceanica on Sicily

E-mail:vohnik@ibot.cas.cz

Tel.: +420271015331

ORCID: 0000-0002-8655-2708

Keywords: fungal endophytes, marine fungi, Posidoniomyces atricolor, Lulwoana, Lulworthiales, Sicily

One-sentence summary: This paper corrects an opinion that "Lulwoana sp." (Lulworthiales) is a dark septate endophyte of the dominant Mediterranean seagrass Posidonia oceanica, because all available evidence suggests that the dark septate endophytic association typical for this seagrass is formed by its specific root mycobiont Posidoniomyces atricolor (Pleosporales).

3

(1)

27

7


- A previous study from Sicily, Italy indicated that the dominant Mediterranean seagrass

\section{Introduction}

Seagrasses are a taxonomically narrow but ecologically important group of vascular plants adapted to permanent life beneath the sea surface (Hemminga \& Duarte 2000). Among the many adaptive traits, they take up mineral nutrients through the leaves, but under oligotrophic conditions, they rely on the roots and the nutrients present in the seabed substrate. While the vast majority of terrestrial vascular plants obtain nutrients through mycorrhizae, i.e., specialized root-fungus organs evolved to help the photoautotroph to scavenge minerals from recalcitrant substrates and the chemoheterotroph to access carbon and energy from photosynthates, seagrasses are regarded non-mycorrhizal (Nielsen et al. 1999). However, their roots do host fungal symbionts (=mycobionts), but their symbiotic modes (e.g., parasitic, pathogenic, endophytic) as well as ecophysiological roles, including a possible role in nutrient uptake, remain unknown. 
Posidonia oceanica is the climax seagrass in the mostly oligotrophic Mediterranean Sea that is often characterized as a "marine desert" (Powley et al. 2017). Phosphorus and nitrogen are the most important limiting nutrients (Estrada 1996) and P. oceanica has to rely on their uptake through the roots (Lepoint et al. 2002). Posidonia oceanica typically colonizes coarse sandy to rocky bottoms, i.e., mostly mineral substrates, but with progressing time, it forms a compact substance composed of degrading leaves, rhizomes and roots mixed in various ratios with sediments and the seabed substrate, which is called matte. Matte can be several meters thick and hundreds to thousands of years old (Mateo et al. 1997) and stores significant amounts of organically-bound mineral nutrients (Romero et al. 1992). These are typically non-available to plant roots without the aid of heterotrophic organisms that decompose organic substrates and release mineral nutrients into the rhizosphere (mostly bacteria and non-symbiotic fungi) or transport them directly to the roots (mycorrhizal fungi). Characterization of the root mycobiota of $P$. oceanica is thus crucial for understanding of the seagrass' mineral uptake and nutrient turnover in its rhizosphere.

One of the first attempts to document fungal colonization and cultivable mycobiont diversity of P. oceanica roots is the study by Torta et al. (2015). These authors visited two localities in NW Sicily, Italy and reported "inter- and intracellular septate mycelium, producing intracellular microsclerotia" that was "detected from the rhizodermis to the vascular cylinder" of the seagrass roots. However, the figures offered by Torta et al. (2015) contradict these claims; for example, the caption of Fig. 3a reads "transverse section with mycelium developing from the rhizodermis to the vascular cylinder" while Fig. 3a actually does not display any intraradical fungal mycelium. Additionally, they isolated a single mycobiont that was subsequently identified as "Lulwoana sp.", based on a 99-100\% ITS rDNA sequence similarity with the GenBank entry KC145432. The authors speculated that this mycobiont is a dark septate endophyte (DSE) and hypothesized that its presence "may help the host in several ways, particularly in capturing mineral nutrients [from rocks] through lytic activity”. However, there is no evidence available that the fungal structures depicted in Torta et al. (2015) actually belonged to this mycobiont, that this mycobiont is a DSE of $P$. oceanica nor that it could help the seagrass in any way. Indeed, the Lulworthiales mainly comprise saprobes inhabiting dead (drift-)wood, corals, herb stems and Foraminifera shells (Kohlmeyer et al. 2000) and despite that they are often recovered from marine algae and seagrasses, it is unknown whether such relationships are biotrophic and beneficial to these hosts. The lulworthioid genus Lulwoana currently contains only one described species (mycobank.org, accessed April 28, 2021), i.e., the lignicolous marine hyphomycete L. uniseptata (anamorph Zalerion maritimum) (Anastasiou 1963; Campbell et al. 2005). Nevertheless, based on the speculations by Torta et al. (2015), Lulwoana has already been cited as "fungal endophyte associated with seagrasses" (Supaphon et al. 2017), "fungal endophyte similar to dark septate endophytes" (Ettinger \& Eisen 2019) and "known endophyte" (Kearns et al. 2019). 
In the same year, Vohník et al. (2015) reported their observations from P. oceanica healthy terminal fine roots collected at several localities in the NW Mediterranean Sea. All their samples displayed a previously undocumented colonization pattern resembling terrestrial DSEs. Subsequently, identical colonization has been reported from dozens of other localities in the NW Mediterranean Sea (Vohník et al. 2017, 2019). In the following year, Vohník et al. (2016) reported the spectra of cultivable fungi isolated from the roots that had been used for the description of the DSE colonization. Surprisingly, they were dominated by a single unknown mycobiont with affinities to Aigialaceae (Pleosporales), with some other isolates belonging to the Lulworthiales. Similar scenario was repeated at many other localities in the NW Mediterranean Sea, also using high-throughput sequencing (Vohník et al. 2017, 2019) and the mycobiont was eventually described as Posidoniomyces atricolor (Vohník et al. 2019). There is convincing microscopic evidence that $P$. atricolor forms the DSE colonization detailed above (Vohník et al. 2019; Vohník 2021). At the same time, although ubiquitous in P. oceanica roots, this fungus has not been reported from any other host or environment. Taken together, these indications suggest a close specific biotrophic relationship of $P$. atricolor with the dominant Mediterranean seagrass.

There is a disagreement between the conclusions presented by Torta et al. (2015) and Vohník and colleagues (see above), mainly concerning the form and the distribution of the fungal colonization in P. oceanica roots. Therefore, I collected the seagrass' roots at eight localities around Sicily and investigated them using light microscopy. At three localities, root mycobionts were isolated into pure cultures and identified using molecular tools. Due to the omnipresence of the DSE symbiosis/ $P$. atricolor in the NW Mediterranean, I hypothesized that they would be present also at the Sicilian localities.

\section{Materials and Methods}

Investigated localities, sampling

I wanted to re-visit the sites investigated by Torta et al. (2015), but their precise location was not possible, because the provided coordinates are "301663E; 4228890N" for San Vito Lo Capo and “378638E; 4209008N” for San Nicola l'Arena. Therefore, I used the locality names combined with their approximate positions in the map presented in that paper and chose two accessible localities at San Vito Lo Capo (S. V. Lo Capo I/IT-78 and S. V. Lo Capo II/IT-79) and one accessible locality close to San Nicola l'Arena (as Trabia/IT-80) (Table 1, Suppl. Fig. 1). Root samples from these localities were used for screening of root fungal colonization by microscopy and mycobiont isolation and identification. In addition, five other localities around Sicily were visited (IT-73 to IT-77, Table 1, Suppl. Fig. 1) and the respective root samples were used only for microscopy. 

their mycobiont in "capturing mineral nutrients through lytic activity", I focused on the part of the $P$. oceanica root system where one could expect the highest nutrient uptake, i.e., the healthy-looking turgescent terminal (=first order) roots (ca. 0.5-1 $\mathrm{mm}$ in diam.). They were collected at various depths and substrates (with the aim to include the shallowest and the deepest $P$. oceanica individuals/patches available as well as to reflect the respective seabed heterogeneity) using scuba diving in August/September 2015. At each locality, root samples were taken from five different P. oceanica individuals/patches at least $5 \mathrm{~m}$ apart, i.e., 40 individuals/patches were sampled in total. The samples for mycobiont isolation were processed within 24 hours from sampling whereas those for microscopy were immediately transferred to $50 \%$ ethanol and stored in a fridge $\left(\right.$ ca. $\left.6^{\circ} \mathrm{C}\right)$ until processed.

\section{Root colonization}

151

152

153

The microscopic screening and documentation of root fungal colonization followed Vohník et al. (2015). The intensity of fungal colonization was estimated based on the presence/absence of typical fungal extraradical and intraradical structures, i.e., superficial hyphae, superficial hyphal parenchymatous sheaths, intracellular hyphae in the rhizodermal cells and intracellular microsclerotia in the "entry cells" (Vohník et al. 2015) and the hypodermis. Ten hand-made longitudinal sections (ca. 3-5 $\mathrm{mm}$ long) from ten random roots were screened per each sampled individual, i.e., 400 sections were screened in total (Suppl. Table 1). No root staining was used. The root colonization was documented using an Olympus BX60 microscope equipped with DIC and an Olympus DP70 camera + QuickPHOTO MICRO 3.2 software (Promicra, Czechia). The Deep Focus mode (Promicra) was employed when beneficial. The photographs were modified for clarity as needed (adjustment of brightness and contrast) using Paint.NET ver. 4.0.13 (https://www.getpaint.net/).

\section{Mycobiont isolation and identification}

Mycobionts were isolated from surface-sterilized root segments (ca. $3 \mathrm{~mm}$ in length) by incubation on potato dextrose agar at room temperature in the dark for 167 days. There were 30 root segments per each of the five individuals/patches per each of the three localities, i.e., 150 segments per locality and 450 segments in total.

PCR was performed using the ITS1F+ITS4 primer pair while the sequencing reaction using the ITS1, ITS1F and/or ITS4 primers. The ITS region of the rDNA was selected because Torta et al. (2015) targeted this gene, despite that phylogeny of the Lulworthiales is based rather on the SSU and LSU rDNA (Campbell et al. 2005; Azevedo et al. 2017). The isolates' molecular identification followed Vohník (2020). Representative sequences of lulworthioid isolates were aligned with those from Torta $e t$ al. (2015), i.e., KF719964-9, and the resulting alignment was used for a delimitation of molecular 
174

175

176

177

178

179

180

181

182

183

184

185

186

187

188

189

190

191

192

193

194

195

196

197

198

199

200

201

202

203

204

205

206

207

208

operational taxonomic units (MOTUs) at $99 \%$ sequence similarity, following a NJ analysis with automatically estimated parameters in TOPALi (Biomathematiscs \& Statistics Scotland). The alignment is available from the author upon reasonable request.

Colony and mycelium morphology of all representative isolates were documented using the same tools as described above for root colonization.

\section{Results}

Root colonization

The great majority of the terminal root sections displayed at least some fungal colonization and the average proportion of non-colonized sections across all localities was only 3\% (min. 0\%, max. 8\%, Suppl. Table 1). At two localities (IT-79 and IT-80), all sections were colonized, in contrast to IT-78 where non-colonized sections reached the highest $8 \%$. Intriguingly, IT-78 is the closest/identical locality to one of the localities investigated by Torta et al. (2015) (i.e., San Vito Lo Capo) and IT-79 lies in its close vicinity.

The average proportion of superficial hyphae (Fig. 1A, B) was high at all localities (min. 92\%, max. 100\%, avg. across all localities 97\%) but the rest fluctuated considerably; the second highest were intracellular hyphae in the rhizodermis (Fig. 1C, D; 56\%, 94\%, 77.8\%) followed by intracellular microsclerotia (Fig. 1E, F; 16\%, 70\%, 41\%) and the least frequent superficial hyphal parenchymatous sheaths (Fig. 1G, H; 4\%, 46\%, 27\%) (Suppl. Table 1).

No new colonization patterns were detected and no macroscopic sporocarps were visible on the surface of the screened roots. Five root segments displayed some infrequent root hairs with terminal swellings (Fig. 1K; max. one segment per locality). Several root hairs were cracked, revealing their spiral cell walls (Borovec \& Vohník 2018; Kolátková \& Vohník 2019).

\section{Mycobiont isolation and identification}

In total, 128 isolates were obtained, corresponding to a ca. $28 \%$ overall isolation success. However, there were apparent differences between the three investigated localities: IT-78 yielded 14 isolates (9.3\%), IT-79 yielded 46 isolates (30.7\%) and IT-80 yielded 68 isolates (45.3\%) (Table 2).

Ten isolates represented unidentified yeasts. Out of the remaining 118 mycelial forms, 114 were identified (Table 2): 56 isolates (49.1\%) represented Posidoniomyces atricolor and 51 isolates (44.7\%) belonged to lulworthioid fungi. There were apparent differences in the recovery of these two mycobiont guilds at two localities: while IT-79 yielded 7 isolates of $P$. atricolor (19\%) and 28 lulworthioid isolates (76\%), IT-80 yielded 43 isolates of $P$. atricolor (67\%) and 17 lulworthioid isolates (27\%). Other isolated mycobionts comprised (alphabetically) Alternaria sp., Cladosporium spp., Corollospora maritima, Fusarium sp., Penicillium sp. and Vishniacozyma victoriae (syn. Cryptococcus victoriae). 
Sequences of representative isolates are deposited in GenBank at NCBI

210

211

212

213

214

215

216

217

218

219

220

221

222

223

224

225

226

227

228

229

230

231

232

233

234

235

236

237

238

239

240

241

242

243

(https://www.ncbi.nlm.nih.gov/genbank) under the accession numbers MW218878-91 (Table 2).

At the $99 \%$ sequence similarity threshold, the lulworthioid fungi obtained in this study were divided into two MOTUs: the majority grouped with the "Lulwoana sp." sequences KF719964, KF719966 and KF719967 from Torta et al. (2015) while two isolates (SIC-121/MW218889 and SIC125/MW218891, Table 1) formed a separate MOTU. In addition, KF719965, KF719968 and KF719969 from Torta et al. (2015) formed another separate MOTU (data not shown). However, whether these MOTUs represent different lulworthioid species cannot be decided based only on ITS rDNA sequences.

All the isolated mycelia were septate and all the representative isolates comprised melanized (light to dark brown) hyphae, especially in later ontogenetic stages (=older colonies) (Fig. 2). On the other hand, only $P$. atricolor colonies originated directly from the intracellular microsclerotia formed inside the P. oceanica root segments (Fig. 2E, F).

\section{Discussion}

In contrast to Torta et al. (2015) and in agreement with several previous studies from the NW Mediterranean Sea (see above), I found the typical DSE colonization pattern in Posidonia oceanica roots at all localities investigated in this study. Likewise, Posidoniomyces atricolor had not been isolated by Torta et al. (2015) but represented up to 67\% (average 49\%) of the isolates identified in this study. The most likely reasons for this difference are the second-order roots investigated by Torta et al. (2015) vs. the first-order roots investigated here and especially the too short cultivation time (four weeks) employed by Torta et al. (2015). Indeed, many obligate marine fungi are notoriously slow growing (up to two years of incubation may be needed for some species, see Kohlmeyer et al. (2004)) and this is also true for P. atricolor whose colonies start to emerge from P. oceanica root segments only after ca. 1.5-2 months of incubation (Vohník et al. 2019).

Comparing the diversity of fungal isolates obtained in Torta et al. (2015) and here is at least to some extent complicated by the identification approach presented in the former, i.e., targeting the ITS rDNA (cf. Campbell et al. 2005; Azevedo et al. 2017) and relying on the first BLAST hit in GenBank at NCBI (cf. Nilsson et al. 2012). Nevertheless, as far as the ITS rDNA sequences can tell, probably only one lulworthioid species had been isolated by Torta et al. (2015) and the same species was detected at all localities investigated here. In addition, probable members of seven other genera were isolated here, suggesting that the seagrass' root mycobiota at the Sicilian localities is not only richer than as reported by Torta et al. (2015) but the richest ever reported in studies employing mycobiont cultivation from surface sterilized P. oceanica root segments (Vohník et al. 2016, 2017; Vohník 2021).

Similarly to some other studies from the NW Mediterranean (see above), P. atricolor colonies were found to develop from intracellular darkly pigmented microsclerotia that occurred in the upper 
layers of the root cortex, suggesting that this mycobiont is indeed responsible for the observed DSE colonization pattern. Torta et al. (2015) reasoned that their "Lulwoana sp." is a DSE, because it formed slow growing colonies "dark in color, with septate mycelium". However, all representative isolates obtained in this study, including ubiquitous opportunistic saprobes also known from terrestrial ecosystems, produced dark septate hyphae in pure culture. This underscores the fact that DSE cannot be recognized based on the appearance of their colonies/mycelium formed outside of the host roots/under in vitro conditions. Instead, they are defined by morphology and color of the structures they produce in the host, i.e., relatively thick melanized septate hyphae colonizing the root surface and forming intracellular resting and storage organs known as microsclerotia (Stoyke \& Currah 1991; Lukešová et al. 2015).

To conclude, this study extends the known range of $P$. atricolor for southern Tyrrhenian Sea/Sicily and provides additional support for the hypothesis that this mycobiont is responsible for the typical DSE colonization pattern observed in the roots of $P$. oceanica. It also confirms that $P$. oceanica root mycobiota regularly comprises related lulworthioid fungi, but their significance and functioning remain unknown. Unlike $P$. atricolor, most of them are relatively easy to culture so they could be used in resynthesis experiments to reveal their actual colonization pattern, possibly with a model nonseagrass hosts, since many endophytes do not seem to be host specific. However, the experimental results available to date indicate negative effects of lulworthioid fungi on their host plants (Hughes et al. 2020).

\section{Acknowledgments}

This work was supported by the Institute of Botany, Czech Academy of Sciences (RVO 67985939). I wish to thank my former student Ondřej Borovec for the help with the sampling on Sicily as well as with the $P$. oceanica root mycobiont isolation and identification, Jiří Machač for assembling Figs 1 and 2 and Paula A. Buil Maldonado for the suggestions on an earlier version of this paper.

\section{References}

Anastasiou C.J. (1963) The genus Zalerion Moore \& Meyers. Canadian Journal of Botany 41

Azevedo E., Barata M., Marques M.I., Caeiro M.F. (2017) Lulworthia atlantica: a new species supported by molecular phylogeny and morphological analysis. Mycologia 109:287-295.

Borovec O., Vohník M. (2018) Ontogenetic transition from specialized root hairs to specific root-fungus symbiosis in the dominant Mediterranean seagrass Posidonia oceanica. Scientific Reports 8:1-11.

Campbell J., Volkmann-Kohlmeyer B., Gräfenhan T., Spatafora J.W., Kohlmeyer J. (2005) A re-evaluation of Lulworthiales: Relationships based on 18S and 28S rDNA. Mycological Research 109:556-568.

Estrada M. (1996) Primary production in the northwestern Mediterranean. Scientia Marina 60:55-64.

Ettinger C.L., Eisen J.A. (2019) Characterization of the mycobiome of the seagrass, Zostera marina, reveals putative associations with marine chytrids. Frontiers in Microbiology 10:1-13. 
Hemminga M.A., Duarte C.M. (2000) Seagrass Ecology. Cambridge University Press. [online] URL: https://www.cambridge.org/core/product/identifier/9780511525551/type/book

Hughes A.R., Moore A.F.P., Gehring C. (2020) Plant response to fungal root endophytes varies by host genotype in the foundation species Spartina alterniflora. American Journal of Botany 107:1645-1653.

Kearns P.J., Bulseco-McKim A.N., Hoyt H., Angell J.H., Bowen J.L. (2019) Nutrient enrichment alters salt marsh fungal communities and promotes putative fungal denitrifiers. Microbial Ecology 77:358-369.

Kohlmeyer J., Spatafora J.W., Volkmann-Kohlmeyer B. (2000) Lulworthiales, a new order of marine Ascomycota. Mycologia 92:453-458.

Kohlmeyer J., Volkmann-Kohlmeyer B., Newell S.Y. (2004) Marine and estuarine mycelial Eumycota and Oomycota. In: Mueller GM, Foster MS, Bills GF (eds) Biodiversity of Fungi: Inventory and Monitoring Methods. Elsevier Academic Press, Amsterdam, pp 533-545. [online] URL: http://dx.doi.org/10.1016/B978-0-12-509551-8.50027-1

Kolátková V., Vohník M. (2019) Adaptive traits in the seagrass Posidonia oceanica: Root hairs with spiral cell walls, not spiral root hairs. Aquatic Botany 155:52-53. [online] URL: https://doi.org/10.1016/j.aquabot.2018.11.013

Lepoint G., Millet S., Dauby P., Gobert S., Bouquegneau J. (2002) Annual nitrogen budget of the seagrass Posidonia oceanica as determined by in situ uptake experiments. Marine Ecology Progress Series 237:87-96. [online] URL: http://www.int-res.com/abstracts/meps/v237/p87-96/

Lukešová T., Kohout P., Větrovský T., Vohník M. (2015) The potential of dark septate endophytes to form root symbioses with ectomycorrhizal and ericoid mycorrhizal middle european forest plants. PLoS ONE 10

Mateo M.A., Romero J., Pérez M., Littler M.M., Littler D.S. (1997) Dynamics of millenary organic deposits resulting from the growth of the Mediterranean seagrass Posidonia oceanica. Estuarine, Coastal and Shelf Science 44:103-110.

Nielsen S.L., Thingstrup I., Wigand C. (1999) Apparent lack of vesicular-arbuscular mycorrhiza (VAM) in the seagrasses Zostera marina L. and Thalassia testudinum Banks ex Konig. Aquatic Botany 63:261-266.

Nilsson R.H., Tedersoo L., Abarenkov K., Ryberg M., Kristiansson E., Hartmann M., Schoch C.L., Nylander J.A.A., Bergsten J., Porter T.M., Jumpponen A., Vaishampayan P., Ovaskainen O., Hallenberg N., Bengtsson-Palme J., Eriksson K.M., Larsson K.-H., Larsson E., Kõljalg U. (2012) Five simple guidelines for establishing basic authenticity and reliability of newly generated fungal ITS sequences. MycoKeys 4:37-63.

Powley H.R., Cappellen P. Van, Krom M.D. (2017) Nutrient cycling in the Mediterranean Sea: the key to understanding how the unique marine ecosystem functions and responds to anthropogenic pressures. In: Mediterranean Identities Environment, Society, Culture. InTech, pp 48-77. [online] URL: http://www.intechopen.com/books/mediterraneanidentities-environment-society-culture/nutrient-cycling-in-the-mediterranean-sea-the-key-to-understanding-how-theunique-marine-ecosystem-f

Romero J., Pergent G., Pergent $\square$ Martini C., Mateo M. $\square$ A, Regnier C. (1992) The detritic compartment in a Posidonia oceanica meadow: litter features, decomposition rates, and mineral stocks. Marine Ecology 13:69-83.

Stoyke G., Currah R.S. (1991) Endophytic fungi from the mycorrhizae of alpine ericoid plants. Canadian Journal of Botany 69:347-352.

Supaphon P., Phongpaichit S., Sakayaroj J., Rukachaisirikul V., Kobmoo N., Spatafora J.W. (2017) Phylogenetic community structure of fungal endophytes in seagrass species. Botanica Marina 60:489-501.

Torta L., Lo Piccolo S., Piazza G., Burruano S., Colombo P., Ottonello D., Perrone R., Di Maida G., Pirrotta M., Tomasello A., Calvo S. (2015) Lulwoana sp., a dark septate endophyte in roots of Posidonia oceanica (L.) Delile seagrass. Plant Biology 17:505-511.

Vohník M. (2020) Ericoid mycorrhizal symbiosis: theoretical background and methods for its comprehensive investigation. Mycorrhiza 30:671-695. [online] URL: https://doi.org/10.1007/s00572-020-00989-1 
Vohník M. (2021) Bioerosion and fungal colonization of the invasive foraminiferan Amphistegina lobifera in a

Mediterranean seagrass meadow. Biogeosciences 18:2777-2790. [online] URL: https://bg.copernicus.org/articles/18/2777/2021/

Vohník M., Borovec O., Kolařík M. (2016) Communities of cultivable root mycobionts of the seagrass Posidonia oceanica in the northwest Mediterranean Sea are dominated by a hitherto undescribed pleosporalean dark septate endophyte. Microbial Ecology 71:442-451.

Vohník M., Borovec O., Kolaříková Z., Sudová R., Réblová M. (2019) Extensive sampling and high-throughput sequencing reveal Posidoniomyces atricolor gen. et sp. nov. (Aigialaceae, Pleosporales) as the dominant root mycobiont of the dominant Mediterranean seagrass Posidonia oceanica. MycoKeys 55:59-86. in the central Adriatic Sea revealed by microscopy, culturing and 454-pyrosequencing. Marine Ecology Progress Series 583:107-120. dark septate endophytic association in the roots of the Mediterranean endemic seagrass Posidonia oceanica. 


\section{TABLES}

\section{Table 1: Localities on Sicily investigated in this study}

\begin{tabular}{|c|c|c|c|c|c|c|}
\hline locality name & locality ID & GPS coordinates & date of collection & collected by & microscopic screening & mycobiont isolation \\
\hline Milazzo & IT-73 & N38.23165 E15.24870 & 31.8 .2015 & O. Borovec & yes & no \\
\hline Capo Passero & IT-74 & N36.66941 E15.12696 & 1.9 .2015 & M. Vohník & yes & no \\
\hline Torre di Gaffe & IT-75 & N37.13954 E13.83171 & 2.9.2015 & M. Vohník & yes & no \\
\hline Sciacca & IT-76 & N37.50342 E13.09337 & 2.9 .2015 & O. Borovec & yes & no \\
\hline Biscione & IT-77 & N37.69905 E12.47618 & 2.9 .2015 & O. Borovec & yes & no \\
\hline San Vito Lo Capo I $^{1}$ & IT-78 & N38.18363 E12.73246 & 3.9 .2015 & O. Borovec & yes & yes \\
\hline San Vito Lo Capo II $^{1}$ & IT-79 & N38.14307 E12.73683 & 3.9 .2015 & M. Vohník & yes & yes \\
\hline Trabia $^{2}$ & IT-80 & N37.99697 E13.65727 & 3.9 .2015 & M. Vohník & yes & yes \\
\hline
\end{tabular}

${ }^{1}$ these localities are identical to or in the immediate vicinity of those investigated by Torta et al. (2015) (see Materials and Methods) 
Table 2: Posidonia oceanica root mycobionts isolated in this study

\begin{tabular}{|c|c|c|c|c|c|c|}
\hline locality ID ${ }^{1}$ & $\begin{array}{l}\text { isolation } \\
\text { success }^{2}\end{array}$ & $\begin{array}{c}\text { total } \\
\text { isolates }\end{array}$ & $\begin{array}{l}\text { total identified } \\
\text { isolates }\end{array}$ & $\begin{array}{l}\text { total Posidoniomyces atricolor } \\
\text { (representatives in GenBank) }^{3}\end{array}$ & $\begin{array}{c}\text { total } \text { Lulworthiales spp. } \\
\text { (representatives in GenBank) }^{3}\end{array}$ & 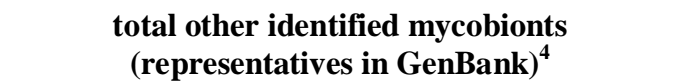 \\
\hline IT-78 & $9.3 \%$ & 14 & 13 & $\begin{array}{c}6 / 46 \% \\
(\mathrm{MW} 218888)\end{array}$ & $\begin{array}{c}6 / 46 \% \\
\text { isolate SIC-121/MW218889 } \\
\text { SIC-125/MW218891 }\end{array}$ & 1x Penicillium sp. (SIC-123/MW218890) \\
\hline \multirow{3}{*}{ IT-79 } & \multirow{3}{*}{$30.7 \%$} & \multirow{3}{*}{46} & \multirow{3}{*}{37} & \multirow{3}{*}{$\begin{array}{c}7 / 19 \% \\
\text { (MW218883) }\end{array}$} & \multirow{3}{*}{$\begin{array}{c}28 / 76 \% \\
\text { SIC-093/MW218884 } \\
\text { SIC-108/MW218886 }\end{array}$} & 1x Cladosporium sp. (SIC-107/MW218885) \\
\hline & & & & & & 1x Alternaria sp. (SIC-110/MW218887) \\
\hline & & & & & & (+7 unidentified bacteria/yeast-like) \\
\hline \multirow{5}{*}{ IT-80 } & \multirow{5}{*}{$45.3 \%$} & \multirow{5}{*}{68} & \multirow{5}{*}{64} & \multirow{5}{*}{$\begin{array}{c}43 / 67 \% \\
(\mathrm{MW} 218882)\end{array}$} & \multirow{5}{*}{$\begin{array}{c}17 / 27 \% \\
\text { SIC-005/MW218878 } \\
\text { SIC-021/MW218879 }\end{array}$} & 1x Corollospora maritima (SIC-023/MW218880) \\
\hline & & & & & & 1x Vishniacozyma victoriae (SIC-025/MW218881) \\
\hline & & & & & & 1x Fusarium sp. (not submitted) \\
\hline & & & & & & 1x Cladosporium sp. (not submitted) \\
\hline & & & & & & (+3 unidentified bacteria/yeast-like) \\
\hline Average/total & $28.4 \%$ & 128 & 114 & $56(49.1 \%)$ & $51(44.7 \%)$ & $7(+10$ unidentified bacteria/yeast-like) \\
\hline
\end{tabular}

${ }^{1}$ locality IDs identical to Table 1

${ }^{2}$ out of 150 surface sterilized Posidonia oceanica fine root segments per each locality (i.e., 30 segments per each sampled individual/patch, see Materials and Methods).

${ }^{3}$ the values after slashes represent $\%$ frequency among all identified isolates

${ }^{4}$ the unidentified bacteria/yeast-like isolates were not included in the total number of isolates nor in the subsequent calculations 


\section{FIGURE LEGENDS}

Figure 1: Dark septate endophytic colonization pattern in the roots of Posidonia oceanica from Sicily

A, B: superficial dark septate hyphae either growing mostly in parallel or following the sulci on the root surface/randomly. C, D: intracellular dark septate hyphae inside rhizodermal cells, note host nuclei in D (asterisks). E, F: early and late stages of microsclerotia development, note frequent connections between two parallel intracellular hyphae in E (arrows). G, H: superficial hyphal parenchymatous sheaths. K: terminal swellings at the end of a $P$. oceanica root hair. No staining was used, photos are from an upright microscope equipped with DIC, for more info see Materials and Methods. Bars A, B, C, E, F, H, K = 20 $\mu \mathrm{m}, \mathrm{D}=10 \mu \mathrm{m}$ and $\mathrm{G}=50 \mu \mathrm{m}$.

\section{Figure 2: Colonial and hyphal morphology and anatomy of representative fungal} isolates obtained in this study

A: Cladosporium sp. (isolate SIC-026) hyphae. B: Lulworthiales sp. (SIC-100) colony morphology and color. C: Lulworthiales sp. (SIC-100) young hyphae. D: Lulworthiales sp. (SIC-100) older hyphae. E, F: Transverse sections through a $P$. oceanica root segment with Posidoniomyces atricolor colonies on its surface, developing in vitro from intracellular darkly pigmented microsclerotia (arrows). Note that the intraradical fungal colonization is restricted to the upper layers of the cortex (incl. the hypodermis) and the rhizodermis, while never reaching the stele. G: Vishniacozyma victoriae (syn. Cryptococcus victoriae) (SIC-025) old colony morphology and color. H: Vishniacozyma victoriae (SIC-025) young mycelium. Bars $\mathrm{A}, \mathrm{C}, \mathrm{D}, \mathrm{E}, \mathrm{F}, \mathrm{H}=50 \mu \mathrm{m}$ and $\mathrm{B}=2 \mathrm{~mm}$, the Petri dish in $\mathrm{G}$ has $8.5 \mathrm{~cm}$ in diam.

\section{Supplementary Figure 1: Localities on Sicily investigated in this study}

Posidonia oceanica root samples were collected in August 2015 at eight localities around Sicily, Italy (IT-73 to IT-80, red circles; locality codes explained in Table 1) and all were checked for fungal colonization using light microscopy. In addition, cultivable fungi associated with the roots were isolated from samples from three localities (IT-78 to IT-80, black dots in red circles). The obtained results were compared with (Torta et al. 2015) whose localities are marked with asterisks. For more details see Materials and Methods. Bar $=20$ $\mathrm{km}$, the map was modified from OpenStreetMap (OpenStreetMap Foundation, for copyright info see https://www.openstreetmap.org/copyright). 


\section{(A)}

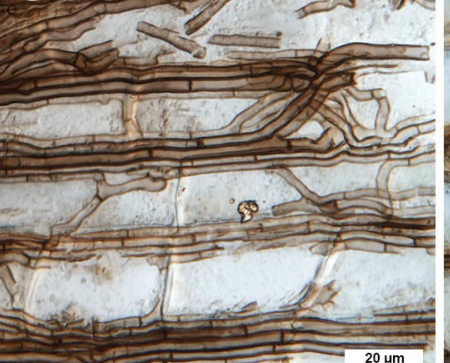

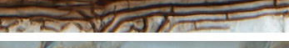

\section{(E)}

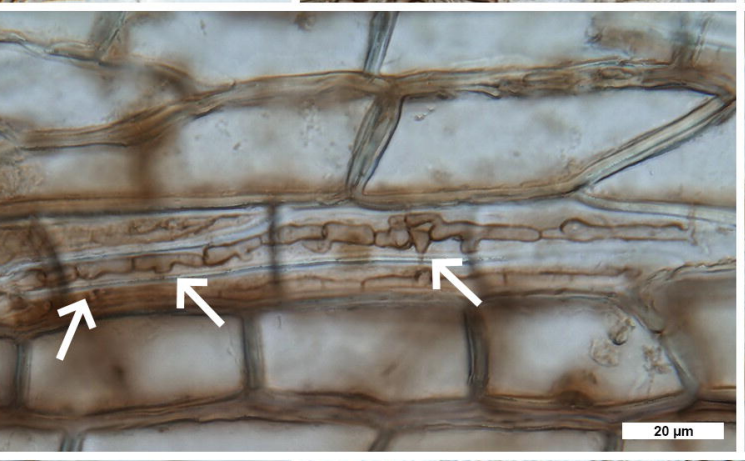

C -20
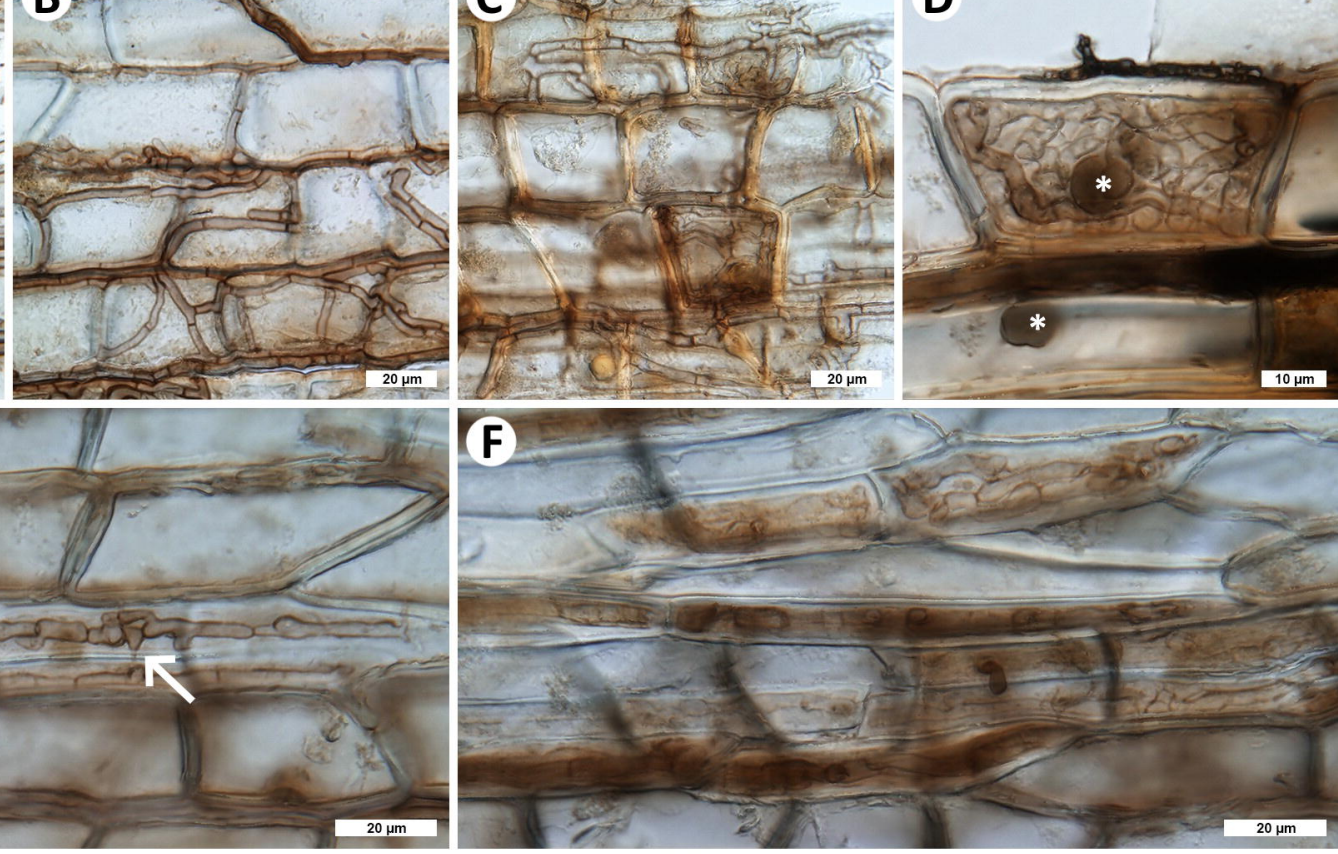

\section{G}

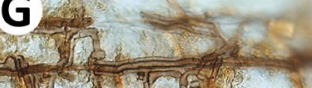

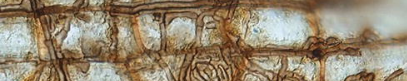

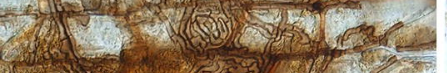

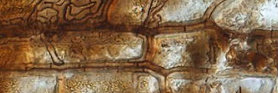

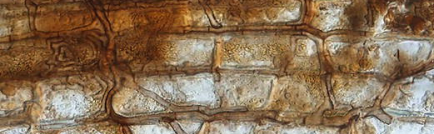
$c^{3}$

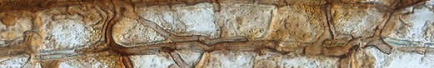
$2 x-1+2 x+2$

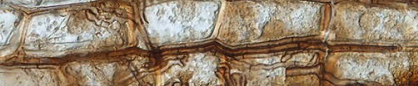

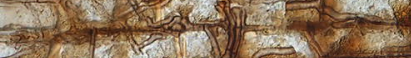

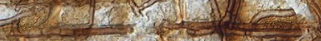
Je. $x$ is $3 y$

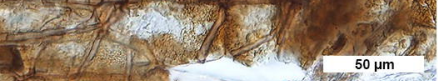

K
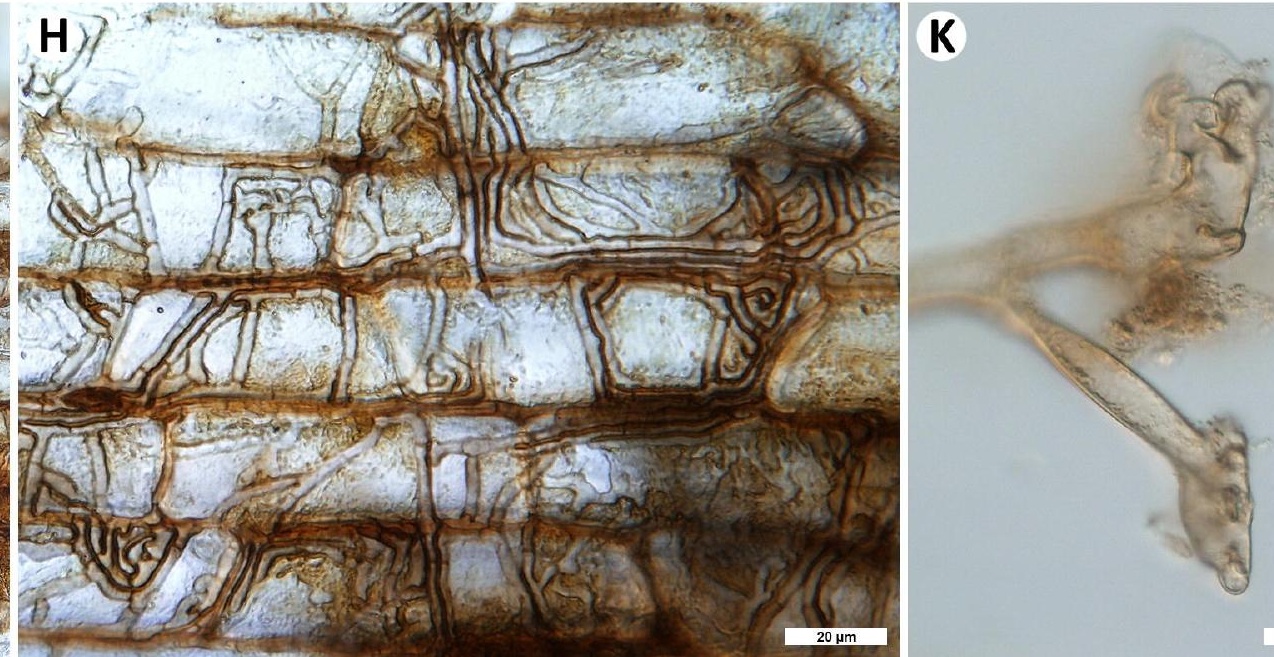

$20 \mu \mathrm{m}$ 


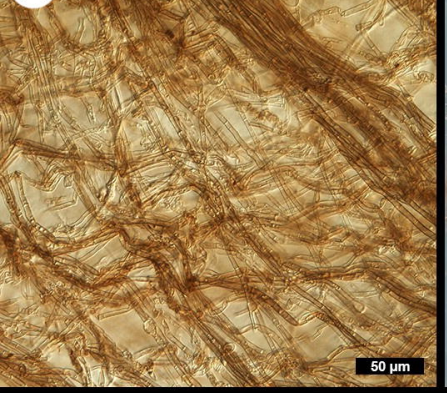

$\mathbf{E}$

3 क. 3.6.

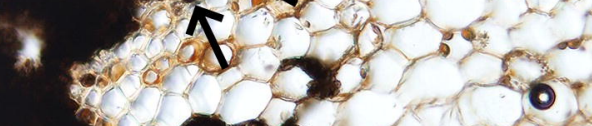

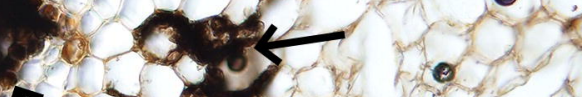

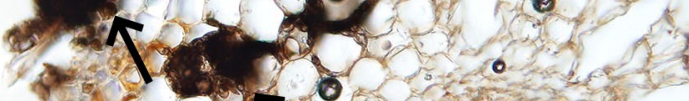

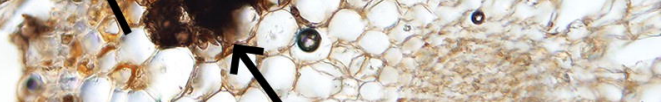

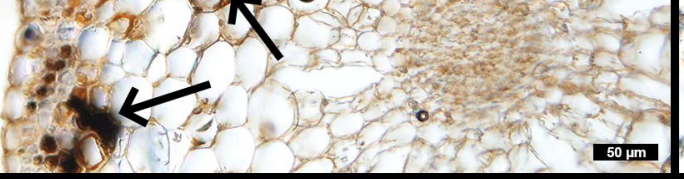

G

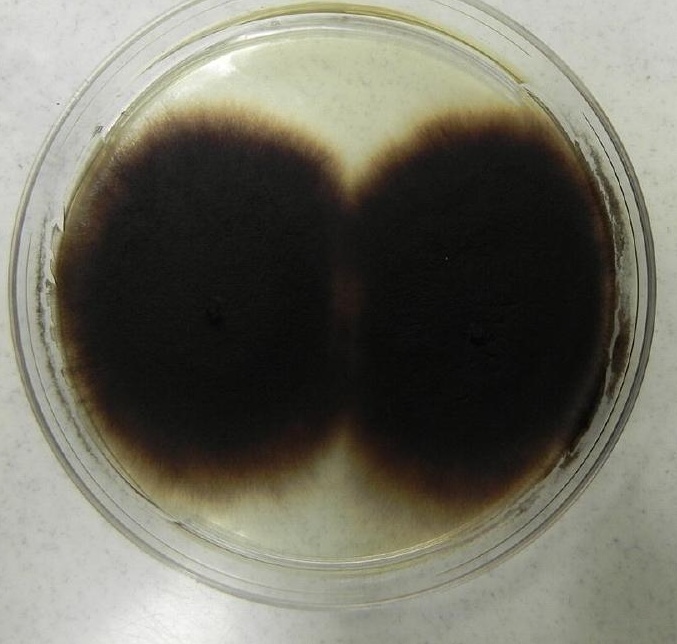

F

$\mathbf{F}$

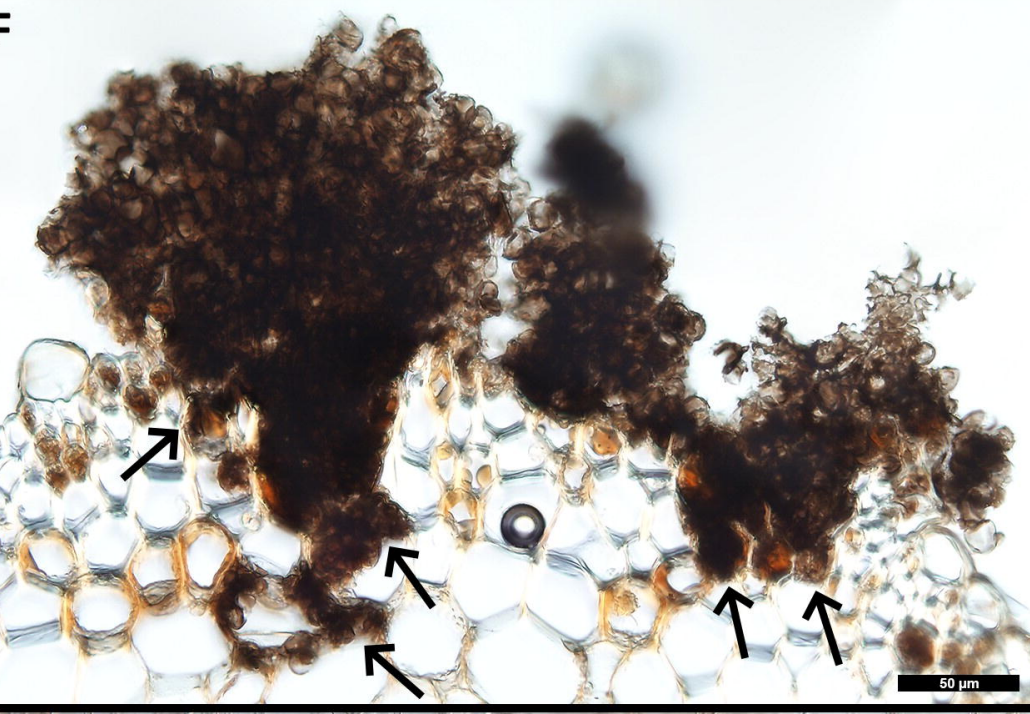

H 